\title{
EL INTERVENTOR Y EL CAÍD. LA POLÍTICA COLONIAL ESPAÑOLA FRENTE A LA JUSTICIA MARROQUÍ DURANTE EL PROTECTORADO DE MARRUECOS (1912-1956)
}

\author{
JOSEP Lluís MATEO DiESTE \\ Universidad Autónoma de Barcelona
}

RESUMEN: La política colonial española en el Protectorado de Marruecos (1912-1956) mantuvo una retórica oficial de respeto al Islam y la justicia marroquí, pero en la práctica introdujo importantes transformaciones en el sistema de jurisdicciones locales e instauró mecanismos políticos de gestión y control de las mismas. Dicha intervención constituyó una forma de justicia indirecta, similar a la fórmula del gobierno indirecto, y en ambos casos contó con numerosas limitaciones materiales o graves problemas de delimitación de competencias entre las autoridades gubernativas y las autoridades judiciales. En este contexto, el sistema de Intervenciones supervisó el funcionamiento y la estructura de la administración marroquí de justicia, y mantuvo una alerta especial hacia todos aquellos asuntos que la administración española consideraba peligrosos para el mantenimiento del orden colonial.

Palabras Clave: Protectorado español en Marruecos. Política colonial. Política religiosa. Justicia marroquí.

ABSTRACT: The Spanish colonial policy in the Protectorate of Morocco (1912-1956) maintained an official discourse of respect towards Islam and the Moroccan justice, but in practical terms the colonizers introduced important transformations in the local system of justice, establishing political mechanisms for its management and control. This intervention was implemented as a kind of indirect justice, similar to the indirect rule system; in both cases this policy displayed several material limitations and it had to afford serious problems of delimitation of competences between government authorities and judicial authorities. In this context, the "Intervenciones» system supervised the functioning and the structure of the Moroccan administration of justice, paying special attention to those affairs that the Spanish administration defined as dangerous for the maintenance of the colonial order.

KEY WORDS: Spanish Protectorate in Morocco. Colonial policy. Religious policy. Moroccan justice. 


\section{INTRODUCCIÓN}

La política colonial española en la zona norte del Protectorado de Marruecos (1912-1956) mantuvo a lo largo de su desigual intervención un tiento especial hacia determinadas esferas de la sociedad marroquí que podían despertar el malestar y el recelo de los colonizados. Entre estas preocupaciones estratégicas de la política oficial española destacaba la religión, y aquellos aspectos que se le consideraban directamente vinculados, como la justicia y la reglamentación del estatuto personal, con especial referencia a la situación de la mujer. Esta política se correspondió sobretodo con aquellos períodos de mayor estabilidad en el control del territorio, puesto que en los momentos más convulsos del conflicto bélico, especialmente durante los años 1920, dichas directrices pasaron bajo el rodillo de la violencia colonial. A partir de los años treinta, la independencia de la justicia local se convirtió en un auténtico objeto de lucha política entre la administración colonial y los nacionalistas urbanos marroquíes, que consideraban inaceptables las intromisiones españolas en dicho ámbito. Cuando los militares golpistas ocuparon la jefatura de la administración colonial en julio de 1936, la independencia de la justicia musulmana reapareció en las negociaciones con los nacionalistas marroquíes y durante la Guerra civil española se incluyó en una agenda política destinada a mantener los clientelismos con las autoridades marroquíes y a legitimar la recluta de soldados para el frente peninsular.

Desde este punto de vista, la dimensión de la justicia continúa siendo una de las grandes desconocidas en la actuación colonial española, y escasos trabajos posteriores al Protectorado se han ocupado del tema de un modo directo, ${ }^{1} \mathrm{y}$ menos aún atendiendo a sus conexiones con la esfera política. En este artículo quiero mostrar el papel que jugó la justicia como objeto de control político y las estrategias que los agentes coloniales españoles adoptaron en este terreno, especialmente en las áreas rurales, organizadas en cabilas o tribus. Partiendo del análisis de las fuentes de la administración del Protectorado ${ }^{2}$ se observa que

1 Feria García, M.: «La justicia indígena de la Zona Jalifiana del Protectorado español en Marruecos» en Awrāq (Madrid), 19 (1998) pp. 143-179; capítulo 2 de La traducción fehaciente del árabe. Fundamentos históricos, jurídicos y metodológicos, Tesis Doctoral, Málaga, Universidad de Málaga, Facultad de Filosofía y Letras, 2001; "Conflictos de legitimidad jurídica en Marruecos: el impacto del Protectorado», en F. Rodríguez Mediano, H. de Felipe: El protectorado español en Marruecos. Gestión colonial e identidades, Madrid, CSIC, 2002, pp. 37-62. ZOMEÑO, A.: «El derecho islámico a través de su imagen colonial durante el Protectorado español en Marruecos», en F. Rodríguez Mediano, H. de Felipe: El protectorado español en Marruecos. Gestión colonial e identidades, op.cit., pp. 307-337. Sobre la organización administrativa en general y el papel de los interventores, véase Villanova Valero, J.L.: El Protectorado de España en Marruecos. Organización política y territorial, Barcelona, Edicions Bellaterra, 2004; Los interventores. La piedra angular del Protectorado español en Marruecos, Barcelona, Edicions Bellaterra, 2006.

2 Las principales fuentes de este artículo son documentales, extraídas del Archivo General de la Administración (en adelante, AGA), Sección de África, de Alcalá de Henares, y la Biblioteca 
la retórica oficial mantenía un respeto diplomático para evitar despertar resistencias entre los marroquíes, pero en la práctica, los administradores coloniales ejercieron una vigilancia discreta e instrumental, de manera que la independencia de la justicia marroquí quedaba restringida cuando los españoles consideraban que el orden colonial se hallaba en peligro. Al mismo tiempo, dicha actuación no siempre contó con la resistencia local, sino que en muchos casos, determinados notables no tuvieron problema alguno en reconocer a una autoridad extranjera que les había colocado o reforzado en sus puestos, y que permitía su arbitrario poder local a cambio del mantenimiento del propio orden colonial.

\section{PRECEDENTES E INSTAURACIÓN DEL SISTEMA JURÍDiCO COLONIAL}

Antes de describir el panorama de jurisdicciones que gestionó la administración del Protectorado, es preciso referir algunos de los precedentes básicos de la acción colonial en el ámbito de la justicia, sus instituciones (tribunales y agencias políticas) y sus actores (jueces, notarios, etc.). Se puede afirmar que la penetración colonial europea en Marruecos se inició por medio del sistema de protecciones. El protegido era un marroquí, musulmán o judío, que adquiría un estatus particular tras convertirse en sujeto adscrito a una legación consular extranjera. El primer tratado entre España y Marruecos que introdujo estas cuestiones fue el Tratado de Marrakech de 28 de mayo de 1767, pero la figura del protegido no recibió un impulso definitivo hasta finales del siglo XIX, como un medio de penetración económica y política de los países europeos. La protección se extendía a la familia y se aplicaba en forma de agentes comerciales (samsara) y de agentes agrícolas (mojalata). La protección beneficiaba a los protegidos con privilegios fiscales y judiciales, puesto que no podían ser juzgados por tribunales marroquíes, y otorgaba a los patronos extranjeros la capacidad de intervenir indirectamente en la economía y la política del imperio jerifiano. La protección se extendió también a personajes religiosos relevantes, y la competencia internacional por penetrar en Marruecos incrementó el número de protegidos, así como su reparto entre diferentes países. Esta situación sacudió los fundamentos de los juristas y los especialistas religiosos locales. La presencia de las potencias extranjeras en suelo marroquí dividió al propio colectivo de ulemas, y a la larga puso en crisis el sistema de producción y transmisión del conocimiento islámico (teológico y jurídico) de los centros predominantes hasta aquel momento, como las universidades Qarawiyin de Fez y Yusufiyya de Marrakech, en las que se formaba a la mayoría de ulemas y demás letrados en materia jurídica ${ }^{3}$.

\footnotetext{
Nacional de Madrid; también utilizaré fuentes orales, a partir de entrevistas que realicé a antiguos administradores españoles del Protectorado, en Madrid, Barcelona y Melilla, entre 1997 y 2000.

3 Eickelman, D.F.: Knowledge and Power in Morocco. The Education of a Twentieth-Century Notable, Princeton, Princeton University Press, 1992.
} 
Con la instauración del Protectorado en 1912, las autoridades coloniales impusieron la legitimidad del derecho español en territorio marroquí para los súbditos españoles. De este modo, la Alta Comisaría creó los Tribunales Hispano-Jalifianos con el fin de dirimir en los asuntos relativos no tan sólo a los ciudadanos españoles residentes en la zona de Protectorado, sino también a los protegidos marroquíes, y a las relaciones entre españoles y ciudadanos marroquíes o extranjeros. Hay que señalar igualmente el precedente de los llamados «Juicios de Moros», celebrados en el Juzgado de Guerra de la Comandancia General de Melilla ${ }^{4}$, que en su mayoría concernían a reclamaciones de deudas, presentadas por «moros del campo» que vendían sus productos a los españoles de la plaza de Melilla, o conflictos sobre alquileres de pisos en Melilla.

En segundo lugar, la población judía del Protectorado quedaba sometida, como antaño, a la justicia rabínica. Así, en 1924 la comunidad de la zona española creó el Alto Tribunal Rabínico, presidido por el Gran Rabino de Tetuán5. Es preciso señalar que los judíos gozaban en el período pre-colonial del estatuto de dhimmis o protegidos del Islam, en este caso del sultán marroquí, aunque ello no evitaba en determinados momentos de tensión los ataques al mellab o barrio segregado. Precisamente, la intervención española desde la guerra de Tetuán (1859-1860) alteró ostensiblemente la posición de los judíos marroquíes, cuyos barrios fueron objeto de ataques por parte de la población musulmana, por considerarlos colaboradores de los europeos. El Protectorado permitió ciertamente a muchos judíos, como previamente el estatuto de protegido, sustraerse al control de la justicia musulmana, y todo ello incidió sustancialmente en las relaciones interreligiosas marroquíes.

En tercer lugar, la población marroquí musulmana pasaba a ser tutelada por diferentes jurisdicciones. Los protegidos serían juzgados por los Tribunales Hispano-jalifianos, pero los casos que afectaban solamente a marroquíes musulmanes dependerían de los tribunales del majzan ${ }^{6}$ y de la justicia islámica. Un caso particular era el de las tropas indígenas coloniales que debían someterse al código español de justicia militar ${ }^{7}$.

Este panorama se mantuvo más o menos intacto hasta la década de los años treinta, cuando la independencia de la justicia musulmana se convirtió en una esfera de negociaciones y polémicas con los nacionalistas marroquíes de ideolo-

4 Lista de 141 juicios celebrados entre 1867 y 1909 en el Juzgado de Guerra de Melilla (Archivo Municipal de Melilla).

5 Ruiz de Cuevas, T.: Jurisprudencia rabinica en Marruecos (La «Hazzaká»), Madrid, Imnasa, 1973; KenBiB, M.: Juifs et Musulmans au Maroc. 1859-1948. Contribution à l'bistoire des relations intercommunautaires en terre d'Islam, Rabat, Publications de la Faculté des Lettres et des Sciences Humaines, Université Mohammed V, 1994.

6 A lo largo del texto mantendré el uso del término majzan para referirme a las estructuras políticas vinculadas al sultanato (al Jalifato en la zona española), y que constituyen una organización de tipo estatal, con todas sus particularidades.

Real Orden de 27-12-1920. 
gía reformista. Para evitar interferencias con los Tribunales Hispano-Jalifianos, la administración del Protectorado emitió en diciembre de 1934 un dahir (decreto) que codificaba la denominada justicia cheránica, de base islámica, remarcando que la misión de los jueces cheránicos de cabila era ocuparse del estatuto personal. En 1938 el gobierno jalifiano reorganizó la jerarquía de los tribunales cheránicos. En su nivel inferior se hallaban los jueces de las ciudades y de las cabilas. Por encima de ellos se situaban los jueces de región, que estaban coronados por el tribunal superior de apelación y el ministerio de justicia. Esta estructura jerárquica reproducía el nuevo mapa político de las regiones diseñado por los colonizadores, y permitía que los funcionarios de la administración marroquí estuviesen supervisados por los funcionarios españoles en cada uno de los escalafones.

La influencia global de estas normativas sobre la justicia estaba muy ligada al desarrollo de la denominada política indígena. El tratado de Protectorado de 1912 enfatizaba la identidad musulmana del país, pero esta declaración de principios contrastaba con la lentitud de la puesta en práctica de las estructuras administrativas previstas en los boletines, ya que, como hemos visto, la justicia cheránica no se regularizó hasta 1934. Además, la intervención en las estructuras de la justicia dejaba en entredicho la neutralidad española en materia islámica. De hecho, la reforma de la jerarquía judicial mencionada más arriba tuvo lugar en un momento de tensiones entre la Alta Comisaría y los nacionalistas ${ }^{8}$. Para contentar a estos últimos, los españoles confirmaron a su principal líder en la zona norte, 'Abd al-Jalek Torres, como ministro de los bienes habús9 en octubre de 1934, pero Torres dimitió en septiembre de 1935, quejándose de la falta de autonomía de su cargo ${ }^{10}$.

Durante la Guerra Civil española, la administración colonial, en manos de los golpistas, favoreció las medidas propagandísticas del respeto de «lo islámico», para contentar a los nacionalistas de Tetuán y legitimar de este modo la recluta de marroquíes para una guerra de no-musulmanes ${ }^{11}$. Entre estas medidas se debe destacar la creación de un Ministerio del Habús y su autonomía administrativa respecto a las autoridades españolas en enero de 1937, o el dabir de 30 de junio de $1939^{12}$, que declaraba la autonomía de la justicia cheránica y

8 PAYE, L.: La politique de la république espagnole au Maroc de 1931 à 1936, París, CHEAM, 1937, p. 10.

9 Bienes inalienables cuyo beneficio se destina a una obra o institución piadosa o religiosa (mezquita, zâwiya, etc.).

10 Wolf, J.: L'épopée d'Abd el Khaleq Torres. Maroc: la vérité sur le Protectorat Franco-Espagnol, París, Eddif-Balland, 1994, p. 191.

11 Franco ofreció a Torres el cargo de ministro del habús, que ocupó desde el 19 de diciembre de 1936 hasta su dimisión el 27 de marzo de 1937. Tras este gesto, la Alta Comisaría reconoció la creación de un consejo sobre el habús, compuesto exclusivamente por marroquíes. En WOLF, J.: L'épopée d'Abd el Khaleq Torres. Maroc: la vérité sur le Protectorat Franco-Espagnol, op. cit., pp. 206-207.

12 Cordero Torres, J.M.: Organización del Protectorado español en Marruecos, II, Madrid, Editora Nacional, 1943, p. 68; LlORD O’LAwlor, M.: Apuntes de derecho administrativo del 
su dependencia directa del ministerio de justicia jalifiano, aunque ello provocara la desconfianza de los propios miembros del ministerio. Es el caso de Si Ahmed 'Abd al-Wahhâb, por entonces secretario del ministro de justicia, quien describía sus dudas respecto a dicha política de respeto aparente, y a la supuesta independencia de la justicia islámica proclamada en $1939^{13}$. A pesar de estos recelos, es preciso recordar que el sistema de gobierno indirecto se basaba en una dependencia mutua entre la administración colonial española y las elites locales que deseaban copar los cargos de la misma. Dicho clientelismo ha sido poco reconocido por la historiografía marroquí, más centrada en destacar los fenómenos de resistencia anticolonial que en estudiar la retroalimentación entre colonizadores y colonizados.

En el caso específico de las zonas rurales, a diferencia de la zona francesa, la administración española se abstuvo de aplicar un estatuto especial para la justicia bereber, como el discutido decreto de 1930 que dividía Marruecos en zonas de jurisdicción islámica y zonas de jurisdicción bereber ${ }^{14}$. Cordero Torres señalaba que conforme al Reglamento de 12 de febrero de 1935 podían «aplicarse por los Tribunales del Caíd las normas consuetudinarias de la región, y con ello las prácticas bereberes de procedimiento o regla jurídica» ${ }^{15}$. Sin embargo, en la práctica, la administración española de asuntos indígenas promocionó la instalación de un sistema jurídico islámico basado en cadíes y en su aplicación de la sharî‘ $a$, que excluía el uso de los códigos locales. Pero tampoco se trataba de una mera imposición: tanto arabófonos como berberófonos compartían la creencia en el prestigio de la cultura árabe y como han señalado autores como Berque, la jurisprudencia islámica se basaba en un compendio entrecruzado de leyes inspiradas en el Corán, en los manuales canónicos de las escuelas jurídicas y en los códigos locales consuetudinarios ${ }^{16}$.

Los cambios fueron más visibles en las zonas rifeñas, no sólo por efecto de los colonizadores, sino también como consecuencia de la política reformista de 'Abd al-Krîm. Hart ha señalado en primer lugar que el 'urf o derecho consuetudinario había empezado a extinguirse a manos del líder rifeño y que la administración española consolidó su transformación y desaparición ${ }^{17}$. Con el Protectorado se redujo el poder de decisión de las asambleas de notables que tenían competencias judiciales, como los consejos de poblado, los consejos de fracción y los consejos de tribu. Hasta la fecha, el consejo del poblado se ocu-

Protectorado de España en Marruecos, Delegación de Educación y Cultura, Tetuán, Editora Marroquí, 1952, pp. 119-122. Este último autor se complacía de la ausencia de protectorado en esta cuestión, a diferencia de la zona francesa.

13 Feria García, M. C.: «Conflictos de legitimidad jurídica en Marruecos: el impacto del Protectorado", op. cit., pp. 7-8.

14 Dabir de 16 de mayo de 1930.

15 Cordero Torres, J.M.: Organización del Protectorado español en Marruecos, II, op. cit., p. 72.

16 Berque, J. Structures sociales du Haut-Atlas, París, Presses Universitaires de France, 1978 (1955).

17 HaRT, D.M.: The Aith Waryaghar of the Moroccan Rif. An Ethnography and History, Tucson, The University of Arizona Press-Viking Fund Publications in Anthropology, 1976, p. 286. 
paba de los robos, de la irrupción en tierra ajena, de los conflictos entre mujeres, de las riñas en general, de asuntos relacionados con la recogida del trigo, la asistencia a la mezquita y la inviolabilidad de los espacios ocupados por mujeres. Con el Protectorado, la estructura centralista del majzan asumió la mayoría de estas funciones, aunque algunas de éstas todavía continuaban en manos de los consejos locales, como la regulación de la altura del trigo para evitar conflictos durante la siega, la vigilancia de los campos durante la misma, la regulación del inicio de la vendimia, el control del ganado, o el reparto del agua. La administración española introdujo sus propias interpretaciones de este sistema y codificó su qanûn (código), afirmando que procedía del 'urf, de la costumbre. Con la centralización y jerarquización del sistema a manos de la administración del Protectorado, estas instancias de base terminaron por recurrir a las instancias de mayor autoridad. Se trataba, por tanto, de la superposición de una estructura centralizada, con sus funcionarios gubernamentales y cheránicos (cadí y notarios), que provocó que el consejo local tuviera que compartir sus competencias con instancias superiores. En el siguiente escalón se encontraba el consejo de fracción, que se reunía una vez por semana en el zoco, bajo un árbol, y se ocupaba básicamente de dirimir conflictos de honor. Durante el Protectorado, el majzan adquirió el control de diversos asuntos tratados por este consejo, como los robos de leña, los conflictos entre familias y linajes, y el control del acceso simultáneo a los zocos de personas del mismo sexo (recuérdese que en el Rif central todavía existen zocos femeninos), mientras que el adulterio y las deudas de sangre pasaron a la jurisdicción cheránica. El majzan colonial absorbió igualmente al consejo de la cabila la jurisdicción sobre las injurias, los asesinatos, las facciones y las deudas de sangre, quedando para la sharî $a$ los casos de adulterio. El capítulo de códigos y multas se transformó también durante la República del Rif (1921-1926) y la implantación colonial. Anteriormente, el importe de las multas se distribuía, según los delitos, entre los linajes afectados y los propios imgharan o jefes. En caso de asesinato, la deuda de sangre quedaba saldada con el pago de la diya a la familia del muerto. Con el Protectorado, la diya quedó bastante restringida y el castigo quedó en manos del majzan, de manera que las instituciones centrales fueron adquiriendo el monopolio de la violencia y del control social en perjuicio de las fuerzas locales. Otra institución rifeña como el juramento colectivo o dhzaddjith ya había sido prohibida en tiempos de 'Abd al-Krîm. Dicho juramento permitía afirmar, ante el alfaquí y el Corán, la inocencia o culpabilidad de un acusado. Sin embargo, estas transformaciones que tuvieron lugar en el Rif central no se pueden extrapolar a todas las cabilas. En la zona de Jebala y en la costa atlántica, las figuras del cadí, el alfaquí o el tâlib tenían un gran asentamiento, incluidas las zonas de montaña que supuestamente habían formado parte de la «anarquía». 


\section{IMÁGENES DE LA JUSTICIA MARROQUÍ EN LA ADMINISTRACIÓN COLONIAL}

La definición de la justicia marroquí por parte de los españoles resultó extremadamente compleja, puesto que no era fácil delimitar las fronteras entre la justicia cheránica y los códigos consuetudinarios, además de las variaciones propias de las diferentes escuelas jurídicas. Nido y Torres (1927) fue uno de los escasos autores que reconoció este cruce de jurisprudencias, y en su manual de justicia incluyó, además de la sharî̀a y de los hadices, las «costumbres jurídicas de las kabilas». Nido destacaba las diferencias entre la justicia de las cabilas árabes y la justicia berberisca, caracterizando a esta última por la elección de jueces árbitro por los propios litigantes, o por la existencia de una asamblea o concejo que confundía atribuciones judiciales, gubernativas y administrativas ${ }^{18}$. A pesar de mostrarse partidario de respetar las instituciones jurídicas bereberes, Nido creía en la superioridad de la justicia cheránica y del majzan, y según su opinión, el fomento de estas últimas facilitaría el acatamiento a la máxima autoridad marroquí de la zona, el Jalifa, y de modo indirecto, a la autoridad española:

«respetando como se debe las instituciones seculares, se abre, repetimos, la puerta para que voluntariamente vayan pasando y sometiéndose a la autoridad superior del Jalifa por medio de los Kadis y Kaides nombrados por él y esto ha de constituir una base muy sólida en que descanse el orden y la tranquilidad pública»19.

La falta de estudios empíricos en el terreno del derecho consuetudinario o el derecho bereber contrasta con la literatura colonial francesa, que generó un voluminoso conocimiento por razones estratégicas orientadas a desarrollar la política bereber ${ }^{20}$. En cambio, en la zona española, la mayoría de oficiales de Intervención, con la excepción de Blanco Izaga, desatendieron la cuestión del derecho consuetudinario ('urf) y los códigos rifeños. La literatura colonial española prestó mayor atención al espacio jurídico de las ciudades y a la necesidad de conocimientos sobre el estado, el régimen de aduanas, así como los tribunales concernientes a la sharî́a y al fiqh. En general, estos trabajos presentaban la administración marroquí de justicia como un sistema contrario a los requisitos de la no contradicción de normas, plagado de ambigüedades y vicios de procedimiento ${ }^{21}$.

18 Nido y TORRES, M.: Guía del español que emprende el camino del conocimiento de la escuela malekita, y cuya Guía es una recopilación de las opiniones principales de los jurisconsultos sobre el derecho musulmán, Tetuán, Editorial Hispano-Africana, 1927, p. 472.

19 Ídem.: p. 475.

20 LAFUente, G.: La politique berbère de la France et le nationalisme marocain, París, L'Harmattan, 1999. El libro ofrece una visión completa de esta política y su conexión con el mundo del conocimiento.

21 Feria García, M.: «Conflictos de legitimidad jurídica en Marruecos: el impacto del Protectorado», op.cit. 
Este conjunto de imágenes no era nuevo. La literatura sobre el Rif de finales de siglo XIX y principios del XX reproducía una serie de tópicos, entre los que destacaba el tema de las deudas de sangre. Los observadores extranjeros utilizaron especialmente esta práctica para demostrar el carácter primitivo y salvaje de los magrebíes. Así, las conclusiones de dichos estudios fueron a menudo utilizadas para legitimar la intervención europea del sultanato, con el fin de restablecer el orden en las zonas anárquicas gobernadas por las deudas de sangre. De este modo, los textos africanistas españoles presentaban la intervención de la justicia como un modo de restablecer el orden político. Dichas concepciones se llevaron al terreno práctico durante el período de la penetración militar. En los informes de los oficiales españoles se describían las venganzas de sangre como las costumbres salvajes de una raza inferior ${ }^{22}$, y los mandos militares manipularon dichas deudas para provocar luchas entre facciones rivales, y convertirse en árbitros de un conflicto que ellos mismos promocionaban. Así lo reconocían los responsables militares de aquella política, como el general Gómez Jordana y el coronel Riquelme, desde la Comandancia Militar de Melilla. ${ }^{23}$ Una maniobra repetida por estos mandos era el desmantelamiento del sistema de multas, fomentando de este modo las venganzas de sangre entre facciones. La multa en especie (diya) que los españoles deseaban suprimir suplía la venganza de sangre «en sí», es decir, la venganza física sobre la familia del acusado. Por consiguiente, su eliminación favorecía el incremento de las agresiones. ${ }^{24}$ En realidad, estos conflictos también venían inducidos, sobretodo en la zona oriental, por la incipiente intervención colonial en materia de adquisición de tierras para explotación agrícola, pero sobretodo para la explotación minera, que generó un mosaico de conflictos locales para obtener las concesiones de los agentes de las empresas capitalistas extranjeras ${ }^{25}$.

Junto a la imagen del marroquí vengativo y primario también existía otra visión idealizada de la sociedad tribal, definida como una sociedad participativa y democrática. A esta doble codificación habían contribuido varios autores de formación etnológica, que dotaron a la deuda de sangre de un carácter ahistórico e inherente al «carácter» marroquí, o definían los consejos de notables bereberes como residuos de un pasado común a los pueblos del Mediterráneo. En

22 «Kabila de Beni Sicar», 1921, p. 53 (Caja MK-18, n 3, IDD 57, AFR, AGA).

23 AYACHE, G.: Les origines de la guerre du Rif, Rabat, SMER, 1982, pp. 113-114. Ayache basa sus datos en los «Documentos de la Comisión de Responsabilidades acerca del desastre de Anual».

24 «la supresión de las multas, lograda por nuestros partidarios (...) se ha traducido en un recrudecimiento de las luchas intestinas dentro de las distintas fracciones», extracción del Boletín Oficial de la Zona de Protectorado Español en Marruecos, 1916, p. 911, citado por MADARIAGA, M. R. de: España y el Rif. Crónica de una historia casi olvidada, Melilla, Ciudad Autónoma de Melilla, 1999, pp. 389-390.

25 Para esta cuestión del impacto de las minas, véase MADARIAGA, R.: España y el Rif, op.cit.; y AZIZA, M.: La sociedad rifeña frente al Protectorado español de Marruecos (1912-1956), Barcelona, Edicions Bellatera, 2003. 
esta línea, los escasos trabajos que se escribieron sobre el derecho bereber en la zona española se debieron a unos pocos interventores o estudiosos próximos a la administración, como Cándido Lobera ${ }^{26}$ o Angelo Ghirelli ${ }^{27}$, aunque el autor español que más destacó en el estudio del derecho consuetudinario rifeño y en la defensa de su aplicación fue Emilio Blanco Izaga ${ }^{28}$. Tras su estancia como interventor en el Rif, el autor alababa los beneficios de mantener en vigor la asamblea local, en contra de las decisiones del majzan. Según Blanco, los funcionarios del majzan, como el caíd y el juez, neutralizaban el carácter democrático de la asamblea y la desposeían de sus funciones económicas y políticas. La crítica de Blanco, no publicada, era más clara, si cabe, en el dominio de la justicia, afirmando que "de parte de la administración española en Marruecos es ridículo no haber protegido al Rif de la contaminación de la Sharia» ${ }^{29}$. La berberofilia de Blanco estaba inspirada en gran parte por la obra del etnólogo francés Robert Montagne. Desde este punto de vista, Blanco atribuía la arabización de los rifeños a la ignorancia española del derecho consuetudinario. Pero el interventor olvidaba que, en realidad, había sido 'Abd al-Krîm el responsable de «arabizar» las instituciones rifeñas y restringir la influencia de sus códigos. También aseguraba que hasta la llegada de los españoles a Marruecos, la sharî'a no era el código dominante, y llegó a afirmar que antes de 'Abd al-Krîm no existía ningún caíd ni cadí en la región ${ }^{30}$. Cabe recordar, en contra de esta argumentación, que el propio padre de 'Abd al-Krîm era juez. Otro autor que se ocupó de la justicia en unos términos similares fue Paniagua y Santos, aunque se limitó a ofrecer una perspectiva normativa, sin datos directos de campo ${ }^{31}$.

26 Lobera escribía que la política referente a las cabilas rifeñas debía seguir la estrategia del general Lyautey de reducir la islamización y mantener las diferencias de los bereberes. LOBERA, C.: «Política rifeña. Principio de la administración de justicia» en Revista de Tropas Coloniales (Ceuta) 21 (1926) p. 193. Según Lobera, estas cabilas veían con disgusto la aplicación de los principios religiosos y se oponían al cadí, que tan sólo era aceptado a condición de que aplicara el derecho consuetudinario.

27 GHIRelli, A.: Monografía de la cabila de Beni Tuzin, Madrid, Gráficas Reunidas S.A., 1923. Esta monografía se basa en datos anteriores al proceso de erradicación de los códigos no «cheránicos», llevado a cabo por 'Abd al-Krîm. El autor aseguraba que Banî Tûzîn eran totalmente independiente del majzan en su organización política y sus códigos jurídicos.

28 El Rif (2a parte. La ley rifeña). II. Los cánones rifeños comentados y «Noticia sobre la yemáa rifeña», en HART, D.M.: Emilio Blanco Izaga: coronel del Rif, Melilla, Ayuntamiento de Melilla-UNED, 1995, pp. 189-204.

29 Ídem.: pp. 205-206.

30 Ídem.: p. 137.

31 Paniagua y Santos, J.: «Notas sobre el derecho consuetudinario de la propiedad en el Rif» en Archivos del Instituto de Estudios Africanos (Madrid) 4 (1948), pp. 7-44. Como en el caso de Blanco, Paniagua defendía la existencia de una identidad ibero-rifeña. Según este jurista, las asambleas bereberes gestionaban los asuntos de la cabila, y su influencia se anteponía al majzan. Paniagua mostraba la hibridación de formas musulmanas y de prácticas locales en el terreno socio-político, aunque exponía la existencia de instituciones rifeñas propias, como las formas de división y transmisión de la tierra y los códigos de compra-venta. 


\section{INTERVENCIÓN ESPAÑOLA DE LA JUSTICIA EN LAS CABILAS}

La consigna de la administración española fue que el interventor no se debía inmiscuir en aspectos que afectaran directamente al «libro», es decir, ni en las decisiones ni en las sentencias emitidas por los jueces, y mucho menos en la transformación de los códigos islámicos. Sin embargo, existen referencias anteriores a 1921 que demuestran la intervención española en materia jurídica. En una de las primeras cabilas que entraron en la órbita española, Banî Shikar, su oficial responsable refería la vigilancia y la intervención en la administración de la justicia y en la ejecución de sus fallos que ejercían las fuerzas de Policía Indígena ${ }^{32}$. En otra cabila cercana a Melilla, Banî Sîdâl, se deducía que los «asuntos pendientes entre indígenas» se resolvían en la cabecera u oficinas españolas, previo informe realizado por el oficial con la ayuda de testigos o «jefes de prestigio». La tramitación iba a cargo del oficial español, asistido por un intérprete, en acuerdo con el cadí, pero la aprobación final de la sentencia recaía en el primero ${ }^{33}$.

Finalizado el conflicto bélico, el reglamento sobre justicia musulmana de 1928 ordenaba «que por los interventores y personal afecto a las Intervenciones deberá vigilarse en todo momento la moralidad de las sentencias y la formalidad del procedimiento de los kadies» ${ }^{34}$. En esta misma línea, un decreto de enero de 1935 autorizaba a la oficina de Intervención a practicar «cuantas diligencias estimen necesarias en el orden criminal y los emplazamientos en el orden civil» ${ }^{35}$. En cualquier caso, el manual de Nido y Torres recomendaba limitarse a controlar los procedimientos, «pues no debe intervenir en el fondo de los asuntos, por tener éstos carácter religioso» ${ }^{36}$.

Para empezar, la propia supervisión de las labores de justicia contaba con una grave limitación. Y es que la mayoría de interventores desconocía el árabe y no podía leer las sentencias, de manera que las labores de interpretación se dejaban en manos de los tulba de las Intervenciones. Éstos debían redactar dos copias de los registros de sentencia, y en caso de observarse alguna irregularidad se consultaba a los asesores jurídicos de las centrales de Intervención. Como mostraré más adelante, todo ello otorgaba un cierto poder a los tulba, qui-

32 «Kabila de Beni Sicar», 1921, p. 63 (Caja MK-18, n³, IDD 57, AFR, AGA).

33 «El kadi emite el fallo koránico que de conformidad con el Capitán u oficial es definitivo», «Kabila de Beni Sidel», Memorias de Kabila 1921, pp. 49-50 (Caja MK-17, IDD 57, AFR, AGA).

34 «Reglas para la organización y funcionamiento de las autoridades cheránicas y el personal que de ella depende en las cabilas», art. 77, Inspección General de Intervención y Tropas Jalifianas, Tetuán, junio de 1928 (Caja 1199, IDD 13, AFR, AGA).

35 «Dahir poniendo en vigor las normas para el cumplimiento de diligencias judiciales por las Intervenciones», 25 de enero de 1935, Boletín Oficial de la Zona de Protectorado Español en Marruecos, Madrid, Ministerio del Estado.

36 NiDo y TORRES, M.: Guía del español que emprende el camino del conocimiento de la escuela malekita, y cuya Guía es una recopilación de las opiniones principales de los jurisconsultos sobre el derecho musulmán, op. cit., p. 477. 
nes podían aprovechar su monopolio de la lengua árabe para dictar sentencias contradictorias con las propias instrucciones del interventor.

El espacio físico para impartir la justicia era la mabkama o tribunal, que debía albergar el archivo de los documentos, y en ausencia de los funcionarios debía ser vigilada por los soldados marroquíes de la Intervención. Las instrucciones españolas insistían en que cada Intervención debía estar cerca del tribunal, aunque, guardando las directrices de la aparente independencia, se decía que «estos locales estarán discretamente separados». Esta segregación espacial entre el interventor y los caídes no siempre había tenido lugar durante los primeros años de implantación colonial. En Quebdana, el oficial español de la Policía Indígena hacía acto de presencia en el tribunal al menos hasta 1921, observando los debates y las sanciones sin intervenir, «exceptuando el caso de notar alguna arbitrariedad» ${ }^{37}$. En la oficina de Suq 'l-Arba'a de Arkemân, el oficial español guardaba el registro de documentos árabes, litigios, transmisión de terrenos, pregones, nacimientos, defunciones y matrimonios, multas, detenciones y expedición de documentos de identidad. A finales de los años treinta, la administración española se quejaba de que el cadí de Banî Tûzîn resolvía en la misma oficina que el interventor durante veinte días al mes, arguyendo que ejercer la justicia en las oficinas o en «mahkamas anexas a la Intervención es mediatizar el libre juicio de los kodats» ${ }^{38}$. Por esta razón, la Inspección de Intervenciones suprimió la práctica de administrar la justicia en las oficinas de Intervención o en los tribunales cercanos a las mismas, y obligó a trasladarlos a los zocos. También ordenaba que el interventor, el caíd y cualquier otra autoridad gubernativa estuvieran ausentes de los tribunales. En este sentido, las instrucciones no se referían tanto a la segregación física como a la no intervención del caíd en las decisiones del juez. Desde la Inspección de Intervenciones se aconsejó prudencia y tiento para mantener la independencia de la justicia a los ojos de los marroquíes, especialmente en el caso de las sentencias de los jueces. La Intervención se limitaría a amparar los recursos de alzada, que se enviarían al delegado marroquí del juez de jueces de la región, «pero nunca impugnando o contraviniendo las sentencias».

En la práctica, los interventores se distanciaron remarcadamente de toda esta serie de directrices o carecieron de los medios materiales para cumplirlas. Según un informe de 1931 sobre la región oriental, la ubicación de los tribunales y la frecuencia de su utilización era la siguiente. La mabkama celebraba sus audiencias coincidiendo siempre con los días de mercado, a excepción de Quebdana, donde tenían lugar el segundo viernes de cada mes, en la antigua oficina de Cabo de Agua, y Banî Tûzîn, donde tenían lugar veinte días al mes en Tlâtâ de Aslâf y Arba'a de Middâr. Teniendo en cuenta que la mayoría de

37 «Kabila de Quebdana», 1921, p. 41 (Caja MK-17, IDD 57, AFR, AGA).

38 Nota sin fecha. Por el contenido se puede datar entre 1929 y 1930 (Caja 1119, IDD 13, AFR, AGA). 
cabilas celebraban un mínimo de dos mercados semanales, y hasta cuatro zocos en otras, como Banî Bû Yahyî, Matalsa, Tamsamân y Banî Awlîshak, cada cabila contaba al menos con dos días en los que se impartía justicia. El horario de la mabkama se adaptaba al del zoco, y solía empezar a las nueve de la mañana. Hay que destacar que en la mayoría de casos, tanto el cadí como el caíd impartían justicia los mismos días de zoco, y a la misma hora. En cuanto a la ubicación de los tribunales, las trece cabilas del informe, las comprendidas en la zona oriental, contaban con un total de treinta y dos locales para administrar justicia. Veintinueve de los edificios eran compartidos por el cadí y el caíd, con locales independientes, y once de los edificios no reunían las condiciones deseables por los españoles. La mayoría de tribunales se emplazaron en los locales de la oficina de Intervención (catorce) o en antiguas oficinas (tres), y en los locales del zoco (nueve). El resto de espacios se improvisaron, aprovechando otras infraestructuras, como las Juntas Vecinales, la habitación de los soldados o un cuartel, y en dos casos se carecía incluso de edificio ${ }^{39}$.

El modelo patrocinado por los españoles se centraba en la sharî́a y en la figura del cadí, aunque tenía también en cuenta la particularidad de las zonas rifeñas. La política religiosa española aconsejaba a los interventores una neutralidad que, en la práctica, estaba supeditada a objetivos de control social; esto es, la Intervención debía fiscalizar la actuación de las autoridades judiciales. Estos cargos judiciales debían ser ratificados por la administración española, pese a que ésta no se inmiscuyera aparentemente en el desempeño de su labor. Así, el reglamento de 1928 establecía la siguiente clasificación concerniente a las «autoridades cheránicas»: cadí (juez), «adul» (notario), «mufti» (emisor de sentencias), perito, «ukala» (defensor en pleitos), «auan» (recaderos y personal auxiliar) y parteras. Es especialmente significativa la inscripción de las parteras en el personal de justicia, ya que sus labores no se limitaban a la pura asistencia en los partos, sino que certificaban la virginidad, los abortos y jugaban un papel importante en las causas de matrimonio, divorcio, adulterios o infanticidios.

El citado reglamento fijaba asimismo las remuneraciones por contratos matrimoniales, ventas, compras, alquileres, escritura de sentencias, documentos de sucesión, exposición de causas, testamentos judiciales, examen de documentos, declaraciones escritas, declaraciones de derecho sobre animales y efectos, envío o salida de notarios, búsqueda de documentos en los registros y honorarios para peritos y auxiliares ${ }^{40}$. El salario de un cadí a mediados de los años treinta era de 2.500 pesetas anuales, mientras que el juez de jueces de la región oriental cobraba 9.600 pesetas, y su auxiliar (un jalifa), 3.600. Estos honorarios

39 «Estado demostrativo de los lugares, días y horas en que se administra Justicia por las Autoridades indígenas de las distintas kabilas de esta Región», Oficina Central de Intervenciones Militares de Melilla, Melilla 20 de julio de 1931 (Caja 1199, IDD 13, AFR, AGA).

40 «Reglas para la organización y funcionamiento de las autoridades cheránicas y el personal que de ella depende en las cabilas», Inspección General de Intervención y Tropas Jalifianas, Tetuán, junio de 1928, pp. 9-14 (Caja 1199, IDD 13, AFR, AGA). 
eran fijos y en pesetas, y se castigaba cualquier otro tipo de remuneración no codificada, como prebendas y sobornos. Los problemas relativos al cobro de honorarios debían ser resueltos por el interventor, "considerado en tal momento como Delegado del Ministro de Justicia». Por su parte, el cadí estaba obligado a apuntar en un registro los siguientes procedimientos: citaciones para apelación, títulos de propiedad de bienes inmuebles y de ventas, matrimonios, divorcios, sucesiones, tutelas, sentencias y talonarios de denuncias.

Visto este amplio abanico de competencias, la pregunta es cómo se delimitaban las labores de los funcionarios de justicia con respecto a la figura de la autoridad gubernativa, el caíd. El manual de Nido y Torres ponía también sobre la mesa esta serie de conflictos de competencias entre el juez marroquí (cadí) y la autoridad gubernativa (caíd), que se mezclaban hasta confundirse en determinados terrenos $^{41}$. El reglamento de 1928 establecía, para deslindar la funciones, que el caíd se debía ocupar de las faltas leves, de la infracción de los bandos de policía, de los delitos penales equivalentes al código penal español en la zona, de los delitos contra la seguridad del estado, del orden público y del régimen político, y de los delitos contra el honor y la honestidad. En el caso de delitos contra la propiedad en los que se conociera a los autores, el caíd debía aplicar los usos y leyes propios de la cabila. Según las instrucciones españolas, eran competencia del cadí la interpretación y administración de la justicia cheránica y los delitos contra la propiedad cuando se desconocían los autores. En otros aspectos no parece muy clara la definición de los aspectos cheránicos, ya que se incluían los «delitos de los empleados públicos en el ejercicio de sus cargos y de los particulares contra el interés público». En caso de conflicto para dirimir el tipo de autoridad que debía intervenir se aplicaba el principio de que «todo asunto deberá ser sometido en su origen a la justicia del kaid», a excepción de los asuntos sometidos a la sharî́a.

Hay que destacar que, a pesar de la supuesta autonomía del cadí, el personal de la Intervención debía vigilar en todo momento sus procedimientos y sentencias. El interventor ejercía en este sentido una especie de «justicia indirecta», al estilo del control ejercido sobre el caíd. El registro de los tulba debía permitir al interventor el control de las sentencias y estar al tanto de los litigios existentes en la cabila. Sin embargo, la falta de conocimientos arabistas de los interventores se les podía volver en su contra, por depender exclusivamente de las traducciones del personal marroquí de la Intervención. En un caso de divorcio, el querellante acudió al interventor para exponerle que el cadí no le hacía justicia, y el oficial español llamó al juez para escuchar su parecer. El cadí, para lavarse las manos, escribió (en árabe) que «de orden del Oficial Interventor fallo aunque no lo creo conveniente $(\ldots) »^{42}$. Este documento oficial circuló por

41 Nido y TORRES, M.: Guía del español que emprende el camino del conocimiento de la escuela malekita, y cuya Guía es una recopilación de las opiniones principales de los jurisconsultos sobre el derecho musulmán, op. cit., p. 469.

42 «Intervención de las autoridades gubernativas y xeránicas...», 1929-1930, carta del Jefe de Intervenciones y Fuerzas Jalifianas (Caja 1199, IDD 13, AFR, AGA). 
la cabila sin el conocimiento del interventor hasta que llegó a una instancia superior, con motivo del nuevo matrimonio de uno de los divorciados.

El reglamento de 1928 estimaba que el sistema judicial propuesto no era aplicable a los sectores de Melilla y Rif, a causa de sus particularidades jurídicas. En primer lugar se planteaba la cuestión de que el idioma rifeño era generalmente desconocido por oriundos de otras cabilas; en segundo lugar, se recordaba que los funcionarios ajenos a estas cabilas ignoraban el derecho consuetudinario en sus diferentes modalidades, que aún se aplicaban en las regiones rifeñas, y que estas cabilas no estaban debidamente preparadas para que individuos ajenos a ellas ejerciesen autoridad y administrasen justicia. Por todo ello, y a diferencia de las otras zonas, se recomendaba que el aspirante a un cargo de cadí en estas zonas fuese natural de las mismas o de sus áreas colindantes.

En términos generales, los litigios y conflictos propios de la vida cotidiana de una cabila eran registrados por el caíd y el cadí, y después eran revisados por la Intervención, que podía actuar cuando consideraba que los asuntos afectaban a la dominación española. Esta supervisión no afectaba tan sólo a las relaciones entre españoles y marroquíes, mediadas por los Tribunales Hispanojalifianos, sino que también se extendía a algunas sentencias aplicadas a los marroquíes. Los litigios, denuncias, conflictos y multas más frecuentes en los registros interventores eran los relativos al honor y el parentesco, y a la propiedad, esto es, los aspectos centrales en la estructura y la dinámica de la sociedad rural marroquí ${ }^{43}$. Por tanto, las Intervenciones se inmiscuían en asuntos que, formalmente, se presentaban como monopolio de las autoridades marroquíes. Esta estrategia política ha podido ser documentada durante los años treinta a partir del propio archivo elaborado por la Inspección General de Intervención y Tropas Jalifianas, que recogía expedientes, por años y por meses, de multas y sentencias en toda la zona de Protectorado. Las fechas de esta documentación no permiten saber si la intervención española continuó en los mismos términos después de la supuesta independencia de la justicia cheránica de 1939. Sin embargo, García Figueras nos ofrece una interesante visión de lo que sucedió después de aquella fecha. Según el delegado de Asuntos Indígenas, el respeto religioso hacia los marroquíes requería tratar con sumo cuidado la independencia de la sharî'a. No obstante, García Figueras recordaba el error de confundir la independencia de la justicia con la abstención de controlar, que era «una verdadera herejía». No se debía intervenir en la tramitación y desarrollo de los asuntos de incumbencia cheránica:

«Pero icuántas armas tiene [el interventor] en su mano!.. Cuando un caso de retraso de tramitación le es conocido puede hacer presente al Kadi la necesidad de activarlo; cuando conozca de un asunto aparente o sospechosamente mal falla-

43 Jamous, R.: Honneur et baraka. Les structures sociales traditionnelles dans les Rif, Londres-París, Cambridge University Press-Maison des Sciences de l'Homme, 1981. 
do, puede y debe promover su elevación en recurso al Kadi Territorial; en todos los casos seguirá y orientará al marroquí para que lo logre; cuando el marroquí carezca de recursos para esa acción de justicia, él se los facilitará. El no interviene en la tramitación ni en el fallo pero ejerce una tutela permanente sobre el marroquí para ponerle a cubierto de cualquier abuso o error» ${ }^{44}$.

Según García Figueras, la no intervención favorecía los conflictos entre el caíd y el cadí, y «la resistencia de los viejos caídes a compartir con ninguna otra autoridad su mando en la Cabila» ${ }^{45}$. Otra cuestión eran los propios atropellos ejercidos por los funcionarios cheránicos, como señaló el Alto Comisario tras un viaje por el Rif que daría pie a la creación de una comisión inspectora de justicia. Estas denuncias incluían los manejos de algún caíd que buscaba deshacerse de un cadí «incómodo», o de rencillas y odios en las cabilas. El interventor no debía abandonar los asuntos exclusivamente en manos del juez, debía respetar su actuación judicial pero también debía observar quien entraba y quien no accedía a la mabkama, para «conocer si trabaja por la justicia o por el dinero» ${ }^{46}$. Además las autoridades judiciales debían mantener su prestigio para que la población marroquí confiara en los interventores, dado que, según García Figueras, la táctica de los nacionalistas era «impedir que el marroquí vaya a la oficina». Lo más sorprendente de las instrucciones de García Figueras sobre la necesidad de cambiar «la no actuación en razón a la independencia de la justicia», era que en los años cincuenta todavía no parecían delimitadas las competencias entre la justicia cheránica (cadí) y la justicia del majzan (caíd). Ello revela la falta de una política coherente por parte de la Alta Comisaría, puesto que ya se venía discutiendo sobre estas cuestiones desde los años veinte.

Para mostrar las paradojas de esta intervención colonial en relación a la justicia, presentaré una serie de casos que permitirán apreciar las dinámicas e interacciones que entraron en juego entre los interventores, las autoridades marroquíes y la población mayoritariamente campesina.

\section{CONFLICTOS POR TIERRAS Y GANADO}

La cuestión de las tierras era crucial para la vida económica local y ello se reflejaba en el tipo de conflictos sociales más frecuentes. Los litigios entre propietarios privados eran más numerosos en épocas de siembra, cuando se marcaban los límites de los terrenos. En Banî Shicar (1921) la mitad de los conflic-

44 «La justicia», serie 1, carta n ${ }^{\circ}$ 1, en García Figueras, T.: Cartas a los interventores, s.a. [1952-1956].

45 «Precisiones sobre la justicia cheránica», serie 1, carta $\mathrm{n}^{\circ}$ 20, en García Figueras, T.: Cartas a los interventores, s.a. [1952-1956].

46 «El interventor y el cadi», serie 3, carta $\mathrm{n}^{\circ} 10$, García Figueras, T.: Cartas a los interventores, s.a. $[1952-1956]$. 
tos contabilizados en 1920 eran relativos a la delimitación de terrenos ${ }^{47}$. La situación de frontera con la zona francesa de muchas cabilas contribuyó a incrementar aún más este tipo de conflictos ${ }^{48}$.

En el caso de las expropiaciones para la colonización, la postura de la Intervención era muy clara. Promover la adquisición de tierras colectivas o privadas, aprovechando la indefinición existente por la falta de títulos de propiedad, o los sobornos de los testigos que los emitían. En la transmisión de bienes inmuebles, el deslinde de la finca debía ser levantado por las autoridades marroquíes, con la presencia del interventor y de los implicados.

El control de la justicia empezaba por los propios funcionarios. Las falsificaciones eran frecuentes y no era extraño que notarios y escribientes vendieran sus servicios. El cadí también podía falsificar su firma si el cliente ofrecía una comisión. Cuando eran descubiertos, el interventor no siempre les destituía, ya que diversos informes reconocían el abuso de los funcionarios pero no especificaban ningún tipo de castigo. Las falsificaciones afectaban principalmente a títulos de propiedad. En Busharia (Banî 'Arûs), una mujer vendió una vaca de su propiedad para que su marido pudiera reintegrar un préstamo agrícola. El marido le había prometido la cesión de un terreno y como ello no se produjo, la mujer fue a denunciar al marido a la oficina de Intervención. El marido se justificó con un documento que resultó ser falso, realizado por un notario y el jalifa del cadí. Tras descubrirse la falsificación, el cadí solicitó una multa y su destitución, pero el fallo debía ser aprobado por la central de Intervenciones, que era quien juzgaba la idoneidad de la decisión ${ }^{49}$. Un caso parecido tuvo lugar en la misma cabila cuando dos notarios emitieron un documento falso, según el cual una mujer vendía un toro a un hombre del mismo poblado. El documento se elaboró a petición del hombre y, descubierto el fraude, el cadí y el interventor acordaron solicitar la baja de los notarios, la publicación de su destitución en los zocos, una multa de 100 ptas. y un mes de cárcel50.

En principio el interventor no se inmiscuía públicamente en estos asuntos, aunque siempre había excepciones, como me contaba un antiguo interventor ${ }^{51}$. Normalmente el interventor no entraba en la mabkama, y aunque saludaba al cadí, no presenciaba los juicios. En una ocasión sí asistió a uno de ellos, por

47 Los datos parecen ciertamente exagerados en relación al tamaño de la cabila, pero así es tal y como se presentan en el informe: «Año 1920. Litigios de terrenos: 1.836; asuntos varios: 964; deudas de sangre: 7. Número de multas: 191», «Kabila de Beni Sicar», 1921, p. 53 (Caja MK-18, $\mathrm{n}^{\circ}$ 3, IDD 57, AFR, AGA).

48 SEDDON, D.: «Le conflit sur la terre à Zaio (Rif Oriental)», Publications du Bulletin Économique et Sociale du Maroc (Casablanca) (1978) pp. 179-197. Este trabajo detalla que el conflicto por las tierras en Awlâd Sattût se prolongó desde la época colonial hasta la década de los setenta.

49 Carta de Eleuterio Peña, jefe de la oficina central, Larache, 23-02-1930 (Caja 1241, IDD 13, AFR, AGA).

50 Carta al t.c. Interventor de Larache, 17-12-1931 (Caja 1241, IDD 13, AFR, AGA).

51 José Ojeda del Rincón, entrevista de 15-09-2000. 
tratarse de un asunto delicado de disputas de tierras con un asesinato de por medio. El acusado se dirigió de rodillas al interventor, gritándole en árabe «sí señor, —quiero- sharấa». El interventor le comentó que el cadí revisaría su caso y le propuso que se pasara por la oficina de Intervención para mantenerse informado de su situación. La reacción del acusado fue muy significativa. Comentó que «fulanito le ha regalado una vaca al cadí, el otro no sé que otra cosa, y yo, que soy pobre, no le he podido regalar nada», con lo cual suponía que se encontraba en desigualdad de condiciones por no poder ofrecer su comisión al juez. Según otro testigo español de excepción, el interventor se encargaba de recibir a personas que se consideraban atropelladas por el caíd o el cadí. En sus recorridos con el teniente coronel Blanco Izaga por la zona norte, su chofer había asistido a multitud de reclamaciones de este tipo ${ }^{52}$. La población asimismo practicaba el ritual conocido como 'âr para reclamar o pedir audiencias. Este tipo de rituales se daba cuando una autoridad importante realizaba una visita, y entonces, los interesados, entre ellos mujeres, le lanzaban piezas de ropa, para que las recogiera en respuesta a su demanda. Las consultas consistían habitualmente en quejas y apelaciones de sentencias.

\section{PARENTESCO Y HONOR}

En la sociedad local, los vínculos de filiación y matrimonio, y las relaciones sexuales entre hombres y mujeres estaban regidas por el fiqh musulmán y eran asunto de los jueces, pero también estaban conformadas por el derecho de costumbre y los códigos de honor, vergüenza y venganza, resueltos frecuentemente por los propios actores o por las autoridades caidales. En cualquier caso, la eventual intervención española en este ámbito se consideraba una intromisión intolerable por parte de la población marroquí. El análisis que hemos podido realizar de una serie de expedientes de la administración española nos permite revelar que desde la oficina de Intervención se observaba esta esfera con cautela. Los documentos, datados a principios de los años 1930, nos ofrecen además reveladores informaciones sobre abusos sexuales cometidos sobre mujeres, su posición de desigualdad frente a la ley, y las prácticas de infanticidio, indicadoras del estigma existente sobre las relaciones ilegítimas. Este tipo de abusos, sumados a los adulterios, forzaban a las mujeres a cometer infanticidio, para eludir los duros castigos que penaban a las madres solteras, o a las madres de padre desconocido. El resto de multas analizadas castigaban irregularidades en el reparto de las herencias o con motivo de las alianzas matrimoniales.

En los casos de abusos sexuales a mujeres marroquíes, los sospechosos mencionados en los informes eran, por orden de frecuencia: hombres marroquíes cercanos a la unidad doméstica (familiares, conocidos o vecinos), soldados de

52 Entrevista con Francisco Rueda (04-04-2000). 
tropas indígenas y algún español. Entre los acusados también encontramos a autoridades marroquíes. En octubre de 1933, la Intervención de Azib de Midar ratificó la condena a un año de cárcel y la destitución del caíd de Tâfarsît, por estar implicado en un caso de infanticidio. A la mujer se la condenó a un año de cárcel, y a la comadrona, a una multa de 25 ptas. ${ }^{53}$. En diciembre de 1933 , se condenó a tres años de cárcel a una mujer de Tamsamân por arrojar a un barranco el cadáver de su hijo recién nacido. La mujer se había casado hacía tres meses, y el marido, ausente, fue exculpado, tras confesar la mujer que había sido violada por un vecino, a quien la Intervención ni tan siquiera se encargó de buscar. En Banî Tûzîn, una viuda fue violada por un sobrino del hermano del difunto. Para evitar la vergüenza y los castigos, intentó abortar con medios medicinales, pero finalmente enterró al recién nacido en el corral. En este caso se especificaba que la central de Intervenciones confirmaba el castigo de un año de cárcel propuesto por el caíd. Por tanto, los infanticidios se realizaban generalmente para esconder relaciones consideradas ilícitas. En un caso de marzo de 1933 la sentencia se emitía siguiendo los dictados de la sharî́a, con el visto bueno del interventor. La condena de un año fue reducida a seis meses, debido a la pobreza de la familia. La inculpada y su madre acusaban a un pariente y a su hermano de violar a la chica, pero éstos salieron absueltos aduciendo que la madre reproducía una eterna pelea entre sus familias. En ocasiones, el infanticidio era consumado por la madre y el padre, para evitar que se descubriera su relación, aunque las penas eran claramente dispares para ambos ${ }^{54}$.

En el ejemplo siguiente se observará el papel del interventor en un proceso que teóricamente quedaba reservado a la justicia musulmana. Una mujer fue acusada de infanticidio, y se inculpó como cómplice al padre, que fue puesto en libertad, mientras que «a dicha mora se impone la sanción que marque el kaid de la kabila, que someterá a aprobación de este centro» ${ }^{55}$. El funcionario español que tomó las declaraciones se puso de parte del hombre, y en el texto criticaba explícitamente a la mujer, según se deduce de la siguiente carta:

«No niega que el hijo sea de él, pero hace constar que no es el único que ha convivido con ella, y pone como ejemplo a un tal Ueld el Mokadden, de Senada (Dar Bunat). En vista de estas manifestaciones, he ordenado su libertad [del supuesto padre], pues nada tiene que ver con el infanticidio, ya que se comprueba por declaraciones de indígenas que lleva cuatro meses fuera de Beni Iffeft. Además, es un chiquillo que no puede ser responsable de que ella lo haya conquistado» [la cursiva es mía ${ }^{56}$.

53 Inspección de Intervenciones, 10-06-1933 (Caja 1241, IDD 13, AFR, AGA).

54 A 27 de julio de 1932 se imponen 3 años de cárcel a dicha mujer y 6 meses para el hombre (Caja 1241, IDD 13, AFR, AGA).

55 Carta al coronel inspector de Fuerzas Jalifianas, Tetuán, 29 de julio de 1930 (Caja 1241, IDD 13, AFR, AGA).

56 Ídem. 
De la misma forma que la superioridad española ratificaba las sentencias, también condonaba penas y multas, incluso en casos de pederastia ${ }^{57}$. La central de Intervenciones en Tetuán no sólo confirmaba sino que proponía castigos. Es el caso de una madre soltera que dio a luz en el Fahs, por lo cual se le impuso una multa de 100 ptas. y 7 meses de cárcel, «y si se considera excesivo, se le impongan 2 meses de cárcel». Finalmente se acordó que cumpliera dos meses en la prisión de Uad Lau si no podía pagar una multa de 150 ptas. ${ }^{58}$. A otras dos madres solteras de Banî Hasan se les impuso el mismo castigo, 150 ptas., «como ejemplo para las demás», y en este caso también se multó a los «indígenas autores de la violación con un mes de cárcel en Uad Lau»59. Asimismo se ratificaba el perdón otorgado por los cadíes. Es la situación de una mujer de Banî Sîdâl, a quien el caíd concedió el pago de una multa en marzo de 1932, tras ser encarcelada en Frajana por infanticidio. A otra mujer de la misma cabila se le dictó una multa de este estilo, aunque ni los funcionarios españoles ni los marroquíes tenían muy claro el destino de la multa.

Los escándalos afectaban a menudo a personas de prestigio. En 1931 se descubrió un sonado enredo entre varias autoridades y los jerifes de Banî Bû Frâh. Un shayj denunció un caso de infanticidio y las acusaciones recayeron en las hermanas de una familia de los jerifes Ajamlishan de la citada cabila, señaladas como culpables de mantener relaciones íntimas con el caíd y el jalifa de la cabila respectivamente. Los efectos de este entuerto fueron una reclamación presentada por los jerifes y la proposición española de destitución del shayj inspirador de las acusaciones, así como las sanciones cheránicas impuestas por el Gran Visir a las jóvenes y a los calumniadores. En este caso se observa claramente que ante el conato de desprestigios, los españoles certificaban la eliminación del personaje de estatus más bajo, el shayj («de malos antecedentes»), el castigo de las mujeres, y la confirmación de los jerifes, el caíd y el jalifa.

El siguiente ejemplo confirma que las sentencias más duras iban destinadas a las mujeres que confesaban el ejercicio de la prostitución. Fue la situación de una viuda de Tamsamân que estranguló a su hijo. El caso fue denunciado por su cuñado. Tras huir y ser capturada confesó que se dedicaba a la prostitución a causa de sus dificultades económicas y que un día, un soldado de Regulares la forzó a mantener relaciones sexuales. La central del Rif confirmó la sentencia del caíd, de cuatro años de cárcel. Los infanticidios a su vez recibían un mayor castigo que las violaciones. De la treintena de casos de violación que he analizado entre 1930 y 1931 (de las centrales de Tetuán, Larache, Chauen y Meli-

57 «A propuesta de la Central de Tetuán, se condona la multa de 300 ptas. impuesta en 9-331 al indígena AbDelmalek B. El Hach Draui, de Hajera Mahal, padre de Mohamed B. Abdelmalek Draui, que violó en unión de otros a un niño, en vista de que carece de bienes», 1931 (Caja 1241, IDD 13, AFR, AGA).

58 Inspección General de Intervenciones y Fuerzas Jalifianas, Tetuán, 02-03-1931 (Caja 1241, IDD 13, AFR, AGA).

59 Central de Tetuán, 27-02-1931 (Caja 1241, IDD 13, AFR, AGA). 
1la) las penas aprobadas por las centrales regionales oscilaban entre uno y tres meses de cárcel, y de 25 a 200 ptas. ${ }^{60}$ Entre las víctimas se encontraban mujeres casadas, una niña de once años, una joven violada por su suegro, y, en general, mujeres que residían en el mismo poblado que el agresor. En los casos de adulterio, como el de un alfaquí, se imponía multa al marido de la adúltera (25 ptas.), a la mujer adúltera (quince días de cárcel) y al adúltero (25 ptas.). La multa más alta, de 500 ptas. y dos meses de cárcel, fue la impuesta a un hombre de Gazawa que había abusado de su sobrina y pretendía casarse con ella. Si la autoridad más cercana no cumplía con la sentencia propuesta por la central de Intervenciones, ésta le castigaba. Es el caso de un muqaddam de Banî Hasan, a quien la central de Intervenciones impuso 50 ptas. de multa por ordenar una paliza contra un tâlib que había intentado violar a una mujer. La siguiente sentencia partió, como las otras anteriores, de la oficina central de la Inspección española. Se trataba de la acusación de un paisano español, por proposiciones deshonestas a una marroquí. Una vaca de la mujer se introdujo en un sembrado del cortijo del español, que se quedó con la vaca. Tras una discusión, la mujer acusó al hombre de proponerle relaciones sexuales a cambio de la vaca. Se impuso una multa de 25 ptas. a cada uno. El hecho de que estos delicados asuntos de musulmanes o de sus relaciones con españoles fueran gestionados por la administración española muestra los límites de la neutralidad interventora en materia de justicia y «moralidad», a pesar de que se mantuvieran formalmente los procedimientos cheránicos.

\section{PolitizaCión DE LOS DElitos}

Los delitos definidos como políticos se referían a la ocultación de armamento, y a la corrupción de las autoridades del majzan: fraudes en el cobro del impuesto del zoco o en la recaudación del impuesto agrícola del tartîb; recolectas ilegales o servicios improcedentes de twiza ${ }^{61}$, así como la eliminación de rivales políticos. Estas corruptelas formaban parte del día a día de los intercambios clientelistas de la arena colonial. Es el caso de un funcionario de poblado de Banî Ysaf, quien obligó a varias personas a que le prestaran su trabajo en calidad de twiza, a cambio de silenciar que se habían negado a facilitar botellas de leche al Consultorio Indígena ${ }^{62}$.

Por parte de los cabileños se daban casos de insultos o de resistencia a la autoridad. Algunos habitantes de un poblado del Hauz escribieron unas cartas

60 Informes de las diferentes centrales regionales de la Inspección General de Intervenciones y Fuerzas Jalifianas, 1930-1931 (Caja 1241, IDD 13, AFR, AGA).

${ }_{61}$ Prestación de trabajo, voluntario u obligatorio, para labores generalmente de interés público (trabajo agrícola, carreteras), pero también de carácter privado, como la construcción de una casa.

62 La Central de Tetuán le impuso un mes de cárcel y 100 ptas. 15-12-1931 (Caja 1241, IDD 13, AFR, AGA). 
a otros poblados vecinos en las que protestaban por la vacunación, por las prestaciones personales y por la lentitud en la reparación de la mezquita. Como castigo ejemplar, la central de Tetuán impuso seis meses de cárcel y 200 ptas. a tres de los implicados, tres meses y 100 ptas. a un faqîh, y dos meses, 200 ptas. y licenciamiento a un muqaddam de Mehal-la ${ }^{63}$. A este tipo de actuaciones colectivas también se imponían multas colectivas, por diversas circunstancias. Como ejemplo, una multa a una comunidad local, por ocultación de ganado robado $^{64}$, y otra por estropear una fuente que el Servicio Agronómico había construido en Kasiba (Banî 'Arûs) ${ }^{65}$. El nuevo sistema de represión castigaba asimismo las críticas a los colaboradores de la oficina de Intervención y les imponía multas. La Intervención de Yebala Central dictó tres meses de cárcel y 300 ptas. de multa para un hombre de Banî 'Arûs que incitaba a los asistentes a la oración de los viernes a impedir la entrada a la mezquita a un amigo del jalifa, al que tildaba de «cristiano» por colaborar con la Intervención ${ }^{66}$.

En las zonas de frontera abundaba el contrabando y las ventas ilegales, en las que también estaban implicadas diversas autoridades. Las sanciones más frecuentes recaían en personas que carecían de permisos o pasaportes para el desplazamiento por las cabilas o para dirigirse a Argelia. La Inspección de Tetuán aprobó una multa de 100 ptas., solicitada por un caíd que castigaba a un muqaddam de su jurisdicción, por ausentarse repetidas veces a la zona francesa sin autorización y dedicarse a vender ganado caballar en la otra zona sin permi$\mathrm{so}^{67}$. En regiones fronterizas como la oriental, los beneficiarios del contrabando no eran exclusivamente las autoridades marroquíes, ya que algunos interventores habrían obtenido de igual modo importantes ganancias, según testigos orales que habían trabajado en oficinas de Intervención y que me rogaron no citar las fuentes.

En esta diversidad de prácticas y castigos, no estaba siempre claro cuál era la institución encargada de impartir justicia ${ }^{68}$. De cara a la población marroquí, el oficial español procuraba que las audiencias y las sentencias fueran presididas por la autoridad marroquí pertinente, ya fuera el caíd o el cadí, pero en muchos casos las multas venían dictadas o corroboradas por las centrales de Intervención.

63 Central de Tetuán, informe de mayo de 1931 (Caja 1241, IDD 13, AFR, AGA).

64 Inspección de Intervenciones, 09-11-1933 (Caja 1241, IDD 13, AFR, AGA).

65 A propuesta de Yebala Central, 04-08-1933 (Caja 1241, IDD 13, AFR, AGA).

66 Nota de 21 de febrero de 1933 (Caja 1241, IDD 13, AFR, AGA).

67 Carta de la central de Tetuán al t.c. interventor de Melilla, Tetuán, 23-10-1930 (Caja 1241, IDD 13, AFR, AGA).

68 Carezco de datos estadísticos sobre estas sentencias para certificar el grado exacto de la intervención española. Las fuentes de la Alta Comisaría y de los tribunales están en su mayor parte por explotar. 


\section{LÍMITES DEL ESTATUTO PERSONAL}

Para terminar presentaré un caso revelador de la actuación española en cuestiones del estatuto personal de los marroquíes: las relaciones mixtas. Los matrimonios mixtos implicaban un desafío a las normas de segregación imperantes tanto en la sociedad española como en la sociedad marroquí. Por esta razón, la Delegación de Asuntos Indígenas inició una persecución de las parejas mixtas, especialmente durante la década de los cuarenta; además, la eventual conversión al cristianismo de los musulmanes que se querían casar con españolas erosionaba el prestigio de los españoles como protectores respetuosos del Islam.

La doctrina española de no intervención quedaba en evidencia en el caso de las relaciones mixtas, entre las que incluiremos las relaciones legales y las relaciones no reconocidas por las respectivas leyes. En este caso entraban en juego la cuestión del respeto del Islam, el papel de la justicia como reproductora del orden social u obstaculizadora de los matrimonios mixtos, y la interferencia de una moral pública que rechazaba la integración de españoles y marroquíes por medio del matrimonio. Las prohibiciones de estos matrimonios ponían en evidencia la voluntad de segregación de ambas sociedades por parte de las autoridades políticas. Por diversas razones, la administración del Protectorado trató de impedir estas relaciones; si se trataba de hombres españoles que querían unirse a mujeres marroquíes, porque ello desafiaba el sistema legal y moral musulmán; y si se trataba de mujeres españolas con hombres marroquíes, porque ello ponía en entredicho la superioridad del colonizador. La Delegación de Asuntos Indígenas, convergiendo con esta actitud dominante, y en la línea pública del respeto de «lo islámico», adoptó una postura de control e impedimento de las relaciones mixtas. Esta voluntad de prohibición se extendió a las relaciones que sí eran permitidas por el sistema local de parentesco. Esto es, el matrimonio entre un hombre marroquí y una mujer cristiana. Su frecuencia llegó a ser relativamente importante, especialmente después de la Guerra Civil española y del desplazamiento de un gran número de marroquíes a la Península ${ }^{69}$. Todo ello conllevó la intervención directa y discreta de la Delegación de Asuntos Indígenas, que se encargó de obstaculizar estas relaciones, en connivencia con las autoridades marroquíes.

Las relaciones mixtas eran desaconsejadas tanto desde el lado español como desde el marroquí, y los impedimentos legales eran numerosos. El Corán y el

69 Sobre este tema véase RodríGuez Mediano, F.: «Delegación de Asuntos Indígenas, S2N2. Gestión racial en el Protectorado Español en Marruecos» en Awrâq (Madrid) 20 (1999) pp. 173206; Mateo Dieste, J.L.: «'Pourquoi tu ne m'écris plus?' Les rapports mixtes et les frontières sociales dans le Protectorat espagnol au Maroc» en Hawwa. Journal of Women in the Middle East and the Muslim World (Leiden) 2 (2003) pp. 241-268; «Amores prohibidos. Fronteras sexuales y uniones mixtas en el Marruecos colonial», en A. Planet, F. Ramos (eds.): Marruecos y España. Una vecindad en construcción, Madrid, Ediciones del Oriente y del Mediterráneo, 2006, pp. 128-159. 
fiqh imponían una serie de impedimentos matrimoniales ${ }^{70}$, entre los que destaca la prohibición de matrimonio entre una musulmana y un no musulmán. A este marco jurídico musulmán se añadían los prejuicios sociales, la endogamia de grupo o la defensa del honor.

En este marco legal, las autoridades españolas emplearon una vez más el principio del respeto al Islam para mantener las fronteras sociales entre colonizadores y colonizados. Por un lado, aceptaban la prohibición para la musulmana de esposar a un cristiano, pero por el otro rechazaban la posibilidad reconocida por el Islam de que una cristiana esposara a un musulmán. En este sentido, las normas emitidas por España aprobaban el argumento de la prohibición del matrimonio de la musulmana con un no musulmán, apelando a una razón de orden público interno ${ }^{71}$. Los matrimonios mixtos eran un auténtico desafío a la segregación entre comunidades y a sus respectivos sistemas de legitimación ${ }^{72}$.

El marco jurídico español estaba marcado por el papel central de la Iglesia católica, que impuso el matrimonio canónico, impidiendo cualquier matrimonio entre personas de confesiones religiosas distintas, y marginando la práctica del matrimonio civil. La instauración de este último se remonta a la revolución de 1868, que aprobó la ley del matrimonio civil, si bien fue derogada al inicio de la Restauración en 1875. En 1887 se volvió a aceptar la fórmula, y el nuevo código civil español de 1889 reconocía dos tipos de matrimonio, el civil y el canónico, en su artículo 42. Este código obligaba a los católicos a seguir la fórmula canónica y asignaba el matrimonio civil a los «no católicos», denominados también «no religiosos». Las personas que se querían casar por la vía civil debían presentar una declaración que demostrara su apostasía ${ }^{73}$. Tras el lapso de la II República, el régimen franquista reintrodujo los privilegios de la Iglesia. La política de la Delegación de Asuntos Indígenas a partir de 1936 venía a

70 (1) Consanguinidad (la madre, la hija, la hermana, la tía paterna y materna, y la sobrina directa), (2) parentesco de leche (en este caso se aplican los mismos impedimentos que en el caso de la consanguinidad, definiendo a la mujer que amamanta como si tratase de la madre), (3) la persona acusada de fornicación, falta de honestidad y adulterio, (4) la persona en período de peregrinación, (5) un hombre no puede esposar a dos hermanas simultáneamente, y (6) la mujer en los períodos de retiro social (en caso de viudedad o repudio).

71 Convención Franco-Marroquí de 30 de marzo de 1912, en GARcía BARriUso, P.: Matrimonio civil de españoles dentro y fuera de España, Tánger, Editorial F. Erola, 1958, pp. 94-95.

72 Clancy-Smith, J.A.: "Islam, Gender and Identities in the Making of French Algeria. 1830-1962», en J. A. Clancy-Smith, F. Gouda: Domesticating the Empire. Race, Gender, and Family Life in French and Dutch Colonialism, Charlottesville-Londres, University Press of Virginia, 1999, pp. 161. Esta autora describe la percepción que las autoridades coloniales tenían de las mezclas como un sabotaje al orden colonial.

73 Martí Gilabert, F.: Política religiosa de la Restauración (1875-1931), Madrid, Rialp, 1991, pp. 100-102. En 1906 se produjo una polémica entre los obispos españoles y el gobierno de Romanones sobre la introducción del matrimonio civil entre católicos. El gobierno aprobó que los matrimonios civiles se pudiesen realizar sin tener que presentar una declaración de religión, pero el gobierno de Maura derogó esta decisión. 
coincidir con este marco legal y con la actitud de la mayoría de juristas españoles, contrarios al matrimonio mixto. Desde el punto de vista de estos juristas, la cultura española, más civilizada, no podía permitir que una mujer adquiriese una condición de esclava. No se podía tolerar que una mujer española, a la que, por cierto, definían como "colaboradora», adoptara un estatus inferior al formar parte de una unidad doméstica polígama:

«Conceden a la mujer una posición muy inferior a la de nuestro país: es más bien una esclava que una colaboradora. No es extraño ver la imagen de una mujer llevando una carga al lado de su marido (...). no se puede tolerar que un indígena ya casado se case con una Española. Tampoco sería aceptable que dé a una española el mismo trato que se le da normalmente a las mujeres indígenas» ${ }^{74}$.

Los jueces españoles aducían todo tipo de impedimentos legales en nombre de la «moral»75. A estos impedimentos se añadía el hecho de que el matrimonio de un español convertido al Islam con una musulmana no era reconocido en territorio español, ya que no se trataba de un matrimonio católico o civil. Además el divorcio islámico y la poligamia también eran revocados por el derecho español ${ }^{76}$.

La confrontación entre las jurisdicciones española y marroquí planteó una serie de problemas, con el siguiente resultado. Según la legislación española, un musulmán podía casarse con una cristiana si obtenía la dispensa por disparidad de culto y se bautizaba. Sin embargo, en 1921 las autoridades españolas extendieron una Real Orden que impedía la inscripción de un matrimonio si el esposo no tenía la nacionalidad española ${ }^{77}$, hasta su revocación en 1949. La celebración del matrimonio mixto también debía ser diferente y el derecho canónico excluía del altar de la iglesia la celebración del rito matrimonial. El espacio ritual se desviaba a la sacristía, ya que la misa quedaba igualmente excluida.

A estas dificultades cabe sumar las barreras formales establecidas por el código español de nacionalidad y la prohibición musulmana de apostasía. El naturalizado español podía perder la nacionalidad cuando volvía a Marruecos por un período igual al tiempo de demanda de su naturalización ${ }^{78}$. Y a los ojos de

74 Lozano Serralta, M.: La nacionalidad en los territorios dependientes (Apuntes sobre la nacionalidad en derecho colonial), Madrid, Instituto de Estudios Africanos, 1955, p. 105.

75 Tras casarse con un judío marroquí, una mujer española convertida solicitó la nulidad de su matrimonio y el tribunal de Tánger (sentencia de 16-11-1948) aceptó su demanda con el argumento de que «el matrimonio hubiera tenido un resultado catastrófico, como todos los de su clase», además de tratarse de una «española pervertida por el judaísmo», GARCíA BARRIUSO, P.: Matrimonio civil de españoles dentro y fuera de España, op. cit., p. 77.

76 El código civil prohibía el divorcio (art. 51 y 83) y castigaba la bigamia (art. 471 y 455 ).

77 Cabe recordar, sin embargo, que algunos marroquíes adquirieron la nacionalidad española, como era el caso de algunos «moros amigos» y de soldados con varios años de servicio en las tropas indígenas.

78 Art. 15 de la Convención de Madrid de 3 de julio de 1880. 
las leyes marroquíes, la apostasía no cambiaba el estatuto jurídico del bautizado, que seguía dependiendo de las autoridades de su país.

La contradicción entre las leyes españolas y las leyes marroquíes dificultó enormemente el matrimonio musulmán entre españolas y marroquíes. De hecho, la ley española no reconocía el matrimonio coránico de españolas cristianas en Marruecos, ya que el consulado exigía la condición de «no catolicidad» de estas mujeres. Esto se contradecía con la propia exigencia musulmana de que la mujer no musulmana que esposara a un musulmán debía seguir alguna de las religiones del libro; esto es, que fuera cristiana o judía. A partir de una disposición legal de 12 de marzo de 1941, estos matrimonios de musulmanes con españolas se anulaban si la mujer no presentaba la prueba de «no catolicidad», o la declaración jurada de no haber sido bautizada. Pese a estos impedimentos, se celebraron algunos matrimonios coránicos y hebraicos de mujeres españolas, según se desprende de la documentación consultada ${ }^{79}$.

La intromisión de la administración española en el estatuto de los marroquíes confirma la hipótesis de la intervención en contra del ideario del respeto. La política de prohibiciones de las relaciones mixtas no se debía únicamente al argumento del prestigio de «raza», sino a la idea de que los matrimonios mixtos ponían en crisis las instituciones y los valores islámicos. Es decir, que la administración española no pretendía cambiar el estatuto personal de los marroquíes, desligándolos de la sharî‘ $a$, ni desvincularlos de la umma de creyentes. En realidad, las autoridades coloniales temían que los marroquíes percibieran estos casos como una maniobra de los españoles para convertir a los musulmanes en cristianos. En principio, la Delegación de Asuntos Indígenas sólo se ocupaba de controlar los elementos políticos anti-españoles, pero no es casualidad que las relaciones mixtas fueran consideradas como un problema político, puesto que ponían en crisis las fronteras entre las comunidades.

\section{CONCLUSIÓN}

La política de la Delegación de Asuntos Indígenas contra los matrimonios mixtos es un ejemplo más de las paradojas de la política colonial española, ya que prohibía la unión de las dos comunidades por medio del matrimonio al tiempo que enunciaba una fusión histórica de «razas» entre españoles y marroquíes. El control ejercido sobre los musulmanes suponía además una intromisión de los colonizadores en la regulación del estatuto personal, regido por leyes islámicas, que era contraria a la propaganda del respeto del Islam.

Pero la intervención colonial en la esfera jurídica local no es más que un exponente de la política colonial implementada en otros ámbitos, puesto que

79 Mateo Dieste, J.L.: «Amores prohibidos. Fronteras sexuales y uniones mixtas en el Marruecos colonial», op. cit. 
los objetivos generales se vieron comprometidos por la falta de medios de la agencia colonial y por las resistencias y acomodaciones de los agentes colonizados. Además, las dificultades encontradas por la administración española a la hora de controlar el ámbito de la justicia se debían en parte al cariz ecléctico de las fuentes legales que componían el aparato judicial marroquí: la sharî‘ $a$, el fiqh, y el 'urf. Además, las Intervenciones encontraron notables obstáculos para definir los cargos que debían impartir la justicia, como refleja la confusión existente hasta los años cincuenta sobre la delimitación de competencias entre el caíd y el cadí. Esta situación indica la enorme influencia adquirida en las cabilas por los caídes, que fueron ganando terreno a los consejos de poblado y de fracción, especialmente en las zonas rifeñas, y reforzando el proceso de eliminación de los cánones rifeños iniciado por 'Abd al-Krîm. Dichos caídes fueron los auténticos beneficiados en la redistribución colonial del poder local, y no es de extrañar que resistieran las reformas propuestas por sus correligionarios urbanos del movimiento nacionalista, a los que acusaban de querer transformar las tradiciones de sus ancestros.

A pesar de estas limitaciones de la acción interventora, la independencia absoluta de la justicia islámica fue una ficción de la propaganda colonial, puesto que las Intervenciones supervisaban la elección y la actuación de los cargos, así como sus sentencias. La vigilancia de los juicios se hacía de un modo discreto, para que la población no sospechara, y en muchas ocasiones los propios cabileños se dirigían a las oficinas de Intervención para presentar quejas, reclamaciones o la revisión de procesos judiciales. Aunque este control era muy superficial y los escribientes marroquíes de la oficina podían manipular las sentencias, debido al desconocimiento del árabe por parte de la mayoría de interventores, también alcanzó cuestiones que, sobre el papel, eran monopolio de la ley musulmana, como era el caso de los infanticidios o los matrimonios. En definitiva, la esfera jurídica atrajo la atención de los colonizadores, puesto que se trataba de un mecanismo central de gestión y control tanto de las autoridades marroquíes como de la población en general. Pero las conclusiones señaladas en este artículo no pueden ofrecer resultados definitivos para todo el período analizado, porque queda por explorar una gran parte de la documentación colonial y la propia dinámica de los tribunales en sus diversas jurisdicciones. En cualquier caso, los datos nos indican el carácter poliédrico de esta situación colonial, con todas sus contradicciones, y revelan la importancia metodológica de contrastar las retóricas oficiales con las prácticas cotidianas de los agentes protagonistas. 